\title{
A Mysterious Cause of Gastrointestinal Bleeding Disguising Itself as Diverticulosis and Peptic Ulcer Disease: A Review of Diagnostic Modalities for Aortoenteric Fistula
}

\author{
Viplove Senadhi ${ }^{\mathrm{a}} \quad$ James C. Brown ${ }^{\mathrm{b}} \quad$ Deepika Arora ${ }^{\mathrm{c}}$ \\ Rebecca Shaffer $^{d}$ Dhiren Shetty ${ }^{\mathrm{e}}$ Peter Mackrell $^{f}$
}

aJohns Hopkins University/Sinai Hospital Program in Internal Medicine, Department of Internal Medicine, Sinai Hospital, Baltimore, Md., bUniversity of Medicine and Health Sciences - St Kitts, New York, N.Y., 'Elmhurst Hospital/Mount Sinai School of Medicine, New York, N.Y., dSinai Hospital, Intermediate Care Unit, Baltimore, Md., 'George Washington University, Washington, D.C., and fDepartment of Vascular Surgery, Sinai Hospital, Baltimore, Md., USA

\section{Key Words}

Diverticulosis · Peptic ulcer disease · Aortoenteric fistula

\begin{abstract}
An 81-year-old male with a history of hypertension, hyperlipidemia, smoking, and peptic ulcer disease (PUD) presented with 2 episodes of maroon stools for 3 days and was found to be orthostatic. His PUD was thought to have accounted for a previous upper gastrointestinal (GI) bleed. A colonoscopy revealed 3 polyps and a few diverticuli throughout the colon that were considered to be the source of the bleeding. Two months later, the patient had massive lower Gl bleeding and developed hypovolemic shock with a positive bleeding scan in the splenic flexure; however, angiography was negative. A repeat colonoscopy revealed transverse/descending colon diverticular disease and the patient was scheduled for a left hemicolectomy for presumed diverticular bleeding. Intraoperatively, an aortoenteric (AE) fistula secondary to an aorto-bi-iliac bypass graft placed during an abdominal aortic aneurysm (AAA) repair 14 years prior was discovered and was found to be the source of the bleeding. The patient had an $A E$ fistula repair and did well postoperatively without further bleeding. $A E$ fistulas can present with either upper GI or lower GI bleeding, and are universally deadly if left untreated. AE fistulas often present with a herald bleed before life-threatening bleeding. A careful history should always be elicited in patients with risk factors of AAAs such as hypertension, hyperlipidemia and a history of smoking. Strong clinical suspicion
\end{abstract}




\begin{tabular}{r|l|l|l}
$\begin{array}{c}\text { Case Reports in } \\
\text { Gastruanteriology }\end{array}$ & $\begin{array}{l}\text { Case Rep Gastroenterol 2010;4:510-517 } \\
\text { DOI: 10.1159/000322662 }\end{array}$ & $\begin{array}{l}\text { Published online: } \\
\text { November 23, 2010 }\end{array}$ & $\begin{array}{l}\text { O 2010 S. Karger AG, Basel } \\
\text { ISSN 1662-0631 } \\
\text { www.karger.com/crg }\end{array}$ \\
\hline
\end{tabular}

in the setting of a scrupulous patient history is the most important factor that allows for the diagnosis of an AE fistula. There are numerous diagnostic modalities for AE fistula, but there is not one specific test that universally diagnoses AE fistulas. Nuclear medicine scans and angiography should not be completely relied on for the diagnosis of $A E$ fistulas or other lower Gl bleeds for that manner. Although the conventional paradigm for evaluating lower Gl bleeds incorporates nuclear medicine scans and angiography, there is evidence that early endoscopy with enteroscopy may have a better role in severe lower Gl bleeding.

\section{Case Presentation}

An 81-year-old male with a past medical history of hypertension, hyperlipidemia, remote smoking, chronic obstructive pulmonary disease (COPD), and peptic ulcer disease (PUD) reported 2 episodes of maroon stools, bright red blood per rectum, and lightheadedness for 3 days. His history was significant for daily intake of baby aspirin with a previous melena episode thought to be secondary to PUD. He had no history of recent melena, abdominal pain, nausea, vomiting, fevers, or chills. The patient was found to be orthostatic and was unsuccessfully managed with intravenous (IV) fluids. An emergency colonoscopy revealed 3 colonic polyps that were removed and diverticuli that were considered the source of the bleeding. Two months later, the patient was re-hospitalized for COPD and had a massive painless hematochezia episode after receiving IV steroids. He developed hypovolemic shock requiring intubation and ICU care. After extubation, the patient had another massive painless hematochezia episode. An initial bleeding scan was negative. The patient had a large transfusion requirement and was stabilized. Unfortunately, he had another episode of massive hematochezia, which prompted a 2nd bleeding scan, which was positive in the splenic flexure and sigmoid colon. The bleeding scan also had increased uptake in the distal abdominal aorta as well as the right common iliac, which was radiologically read as physiological blood pooling that did not meet criteria for active lower gastrointestinal (GI) bleeding (fig. 1). However, angiography did not reveal a specific bleeding site (fig. 2). The patient continued to have active hematochezia with hypotension, even after receiving 9 units of blood. The differential diagnoses of diverticular bleed, PUD, arteriovenous malformations, and severe hemorrhoids were considered. A repeat urgent colonoscopy revealed transverse and descending colon diverticular disease, which warranted a left hemicolectomy. In the operating room, the patient was found to have a previous abdominal aortic aneurysm (AAA) and an aortoenteric (AE) fistula secondary to the stent that was placed during his AAA repair 14 years prior. The patient underwent an exploratory laparotomy with a total abdominal colectomy and excision of the AE fistula. The massive lower GI bleed in the form of hematochezia and melena history was secondary to a right iliac artery aneurysm with an AE fistula. The patient was in good health at a one-year follow-up.

\section{Discussion}

AE fistulas are grouped as either primary or secondary in nature. Causes of primary AE fistulas include atherosclerotic AAAs prone to rupture, radiotherapy, prosthesis, and tuberculosis [1]. Primary AE fistulas most often occur at the 3rd portion of the duodenum [1]. Secondary AE fistulas can occur after AAA repair, and graft infection is the leading cause of AE fistulas [2]. This complication occurs with $0.4-3.1 \%$ of grafts in AAA repair, as was the case with our patient $[2,3]$. Secondary AE fistulas may present at the duodenum $(81 \%)$ or the ileum (10\%), but are generally proximal to the AAA graft [2]. In addition, extra-graft sites of infection such as an inflamed appendix, can result in an infected graft leading to a secondary AE fistula as described in a rare case by Lauwers [4].

AE fistulas can present with symptoms of upper or lower GI bleeding, which can be confounding. Most patients have an initial herald bleed, manifested by hematochezia, and 


\begin{tabular}{r|l|l|l}
$\begin{array}{c}\text { Case Reports in } \\
\text { Gastruanterology }\end{array}$ & $\begin{array}{l}\text { Case Rep Gastroenterol 2010;4:510-517 } \\
\text { DOI: 10.1159/000322662 }\end{array}$ & $\begin{array}{l}\text { Published online: } \\
\text { November 23, 2010 }\end{array}$ & $\begin{array}{l}\text { O 2010 S. Karger AG, Basel } \\
\text { ISSN 1662-0631 } \\
\text { www.karger.com/crg }\end{array}$ \\
\hline
\end{tabular}

then a massive bleed causing hypovolemic shock, as in our patient. The classic triad of abdominal pain, a pulsatile abdominal mass, and GI bleeding only occurs in $11 \%$ of patients [5]. The key to diagnosis is a high index of suspicion in the setting of an AAA repair in the past, which in our patient failed to be elicited in his initial history.

There are many modalities that may aid in the diagnosis of an AE fistula, but without strong clinical suspicion, these modalities may be futile. For example, the role of computed tomography (CT) in the diagnosis of AE fistulas is also limited (fig. 3 ). The typical sign of a bleeding AE fistula on a contrast enhanced CT is perigraft contrast medium extravasation [2]. Unfortunately, this finding is absent if the rate of bleeding is slow. However, CT images may be useful in identifying features that are often associated with AE fistulas, such as graft site infections. Signs found on CT imaging of the abdomen that may indicate graft infection include perigraft or intraluminal gas, fluid, or tissue thickening [3]. In addition, CT may demonstrate a pseudoaneurysm [2]. More useful images may be possible with multidetector computed tomography (MDCT), even if the rate of bleeding is slow, due to the higher image quality.

What is the role of a nuclear medicine bleeding scan in localizing bleeding in an $\mathrm{AE}$ fistula? A nuclear medicine bleeding scan is often employed in severe lower GI bleeds and is often considered by many internists to be pivotal in the management of lower GI bleeding. However, there are numerous pitfalls of nuclear medicine scans in the evaluation of bleeding, especially in the paradigm of lower GI bleeding. As seen in our case, the nuclear medicine scan was falsely negative on the 1st occurrence and was misleading in the 2nd scan. This led to a false diagnosis of massive hematochezia secondary to diverticulosis. Understanding the basics of the study is a necessity in the ideal management of GI bleeding. A normal abdominal $99 \mathrm{mTc}$ red blood cell (RBC) scan highlights blood pooling in vascular organs such as the heart, liver, spleen, kidneys, colon, gallbladder, male genitalia, and the uterus in females [6]. Thus, if blood pools in a location secondary to decreased or accelerated GI motility, a false positive may be elicited. It is commonly known that blood itself has a cathartic effect and this may further cloud the results of a nuclear medicine scan. In our patient, the AE fistula had repeatedly bled and at the time of the nuclear medicine scan, the blood had left its origin in the ileum. The blood was found in the splenic flexure at the time of the nuclear medicine scan. Due to diverticular disease predominance in this area and the patient's history of diverticulosis, the diagnosis of a severe diverticular bleed that warranted surgery was made. This was a false diagnosis based on a positive nuclear medicine scan, which led the patient to a possibly unnecessary colectomy and potential harmful complications.

The 1st nuclear medicine scan was negative most likely due to the cathartic effect of the blood and the intermittent bleeding associated with AE fistulas. The intermittent bleeding of AE fistulas has been well described in the literature secondary to 2 factors: automatic closure of the bleeding fistula that may occur due to decreased blood volume and clot formation at the site of the fistula [5]. The pattern described is very similar to the classic presentation of a diverticular bleed, which also presents with intermittent bleeding. Additionally, the mechanism of clot formation in AE fistulas is similar to clot formation in PUD, which provides some etiology as to why AE fistulas may mimic PUD in some settings especially when melena is present, which occurred in our patient prior to his ICU admission. Many patients with an AE fistula suffer secondary renal insufficiency due to the severity of their bleeding, leading to massive renal azotemia. This also confounds bleeding scans as renal excretion of $99 \mathrm{mTc}$ results in the accumulation of the markers in 


\begin{tabular}{r|l|l|l}
$\begin{array}{c}\text { Case Reports in } \\
\text { Gastroenterology }\end{array}$ & $\begin{array}{l}\text { Case Rep Gastroenterol 2010;4:510-517 } \\
\text { DOI: 10.1159/000322662 }\end{array}$ & $\begin{array}{l}\text { Published online: } \\
\text { November 23, 2010 }\end{array}$ & $\begin{array}{l}\text { O 2010 S. Karger AG, Basel } \\
\text { ISSN 1662-0631 } \\
\text { www.karger.com/crg }\end{array}$ \\
\hline
\end{tabular}

different areas, most notably in the ureters and bladder [6]. In addition, the stomach may also accumulate pertechnetate, which can be visualized on a normal scan [6].

Incidental findings may also be discovered when RBC scintigraphy is utilized to investigate suspected lower GI bleeding. Incidental findings such as hepatic hemangiomas, great vessel tortuosity, AAA, colonic varices, arteriovenous malformations, osseous activity, gallbladder, and occluded iliac vessels may mislead physicians as to the etiology of lower GI bleeding and demonstrate the poor sensitivity of the scan, especially when the etiology of the bleed is unknown [6]. However, the lack of specificity of the scan can also result in the misdiagnosis of incidental findings and may lead to improper management of life-threatening conditions, as exemplified in our case. Causes of false positive results in RBC scintigraphy can also occur from hyperemia resulting from inflammation of various causes, which can be especially misdirecting [6]. In addition, even saliva can mislead results, as saliva-containing unbound $99 \mathrm{mTc}$ can result in false positives if transit time is rapid enough [6].

Another key factor to consider in interpreting nuclear medicine scans is that they capture a particular moment of time which may lead to many false positives. The amount of delay employed between images taken in sequence can be used as a means of differentiating various causes of $99 \mathrm{mTc}$ accumulation. However, miscalculations and unexpected delays may also result in false positives. For example, Crooke and Currie [7] describe a case in which diffuse accumulation of marked RBCs in the stomach resulted from an episode of frank epistaxis in which the patient swallowed a large amount of blood. However, identical findings can be most commonly associated with GI bleeding or simply an accumulation of free $99 \mathrm{mTc}$ [7].

Abdominal CT (as mentioned above) and aortography may be useful adjunctively in confirming the diagnosis of AE fistula, but may be unreliable as seen in our patient [8]. The initial evaluation of a suspected AE fistula should include esophagogastroduodenoscopy (EGD) in order to identify the 3rd section of the duodenum, which may demonstrate extrinsic lumen compression, in addition to ruling out other potential causes of bleeding [2]. In some cases, the graft may be visualized during the study. Regardless of the investigators' index of suspicion, fewer than $40 \%$ of AE fistula cases reveal evidence of bleeding on EGD [2]. In this instance, push enteroscopy may be used in order to investigate more distal portions of the small bowel [9]. Unfortunately, the diagnostic yield of video push enteroscopy has been reported to be as low as $15 \%$ for distal lesions that are out of reach of a conventional endoscope in patients with obscure GI bleeding [9]. However, there have not been adequate studies regarding whether double-balloon enteroscopy or spiral enteroscopy is of value in AE fistula diagnosis. Both double-balloon enteroscopy and spiral enteroscopy are endoscopic procedures that incorporate complete small bowel transgression and may have more yield in AE fistula diagnosis, given the variability in location of AE fistulas. AE fistulas are most commonly located in the $3 \mathrm{rd}$ or 4 th portion of the duodenum. Theoretically, spiral enteroscopes and double-balloon enteroscopes should have moderate utility in the diagnosis of AE fistulas, but this has not been validated. There are current studies which are testing the utility of EGD with spiral enteroscopy in GI bleeds in the emergency room, which may validate the utility of early enteroscopy in GI bleeds. Angiography is another modality known to be useful in the diagnosis of $\mathrm{AE}$ fistulas. Due to the typical intermittent bleeding pattern of $\mathrm{AE}$ fistulas, angiography is of limited use as a diagnostic tool, as seen in our case. The rate of bleeding must be a minimum of $0.5 \mathrm{ml} / \mathrm{min}$ in order for angiography to provide a 


\begin{tabular}{r|l|l|l}
$\begin{array}{c}\text { Case Reports in } \\
\text { Gastruanteriology }\end{array}$ & $\begin{array}{l}\text { Case Rep Gastroenterol 2010;4:510-517 } \\
\text { DOI: 10.1159/000322662 }\end{array}$ & $\begin{array}{l}\text { Published online: } \\
\text { November 23, 2010 }\end{array}$ & $\begin{array}{l}\text { O 2010 S. Karger AG, Basel } \\
\text { ISSN 1662-0631 } \\
\text { www.karger.com/crg }\end{array}$ \\
\hline
\end{tabular}

significant diagnostic yield, which results in an overall sensitivity of $20 \%$ for lower GI bleeding [2].

Thus, the diagnosis of AE fistulas can be extremely difficult and therefore, it is not surprising that most diagnoses are made in emergent laparotomy. Even with laparotomy, there is some discrepancy regarding the accuracy of diagnosis. Kaushik [10] noted that laporatomy may be negative in $50 \%$ of cases and that despite various diagnostic techniques, as many as $50 \%$ of cases are diagnosed post-mortem [11]. The mortality rate for an untreated AE fistula is $100 \%$ and emergent surgery is the treatment of choice in the setting of secondary GI bleeding [10].

There has been evidence for a paradigm shift in the evaluation of severe hematochezia, which was the key diagnostic dilemma in our patient. The traditional approach emphasizes that severe hematochezia should be evaluated by emergency angiography for diagnosis and embolization [12], which was attempted in our patient. If angiography is unsuccessful, the traditional approach favors surgery such as subtotal colectomy for diverticulosis, which also occurred in our patient. The diagnostic yield of angiography is low in many cases. A comparative study of emergency angiography versus colonoscopy in severe hematochezia was close to $10 \%$ for angiography and $80 \%$ for colonoscopy [12]. The traditional approach then suggests that surgery be the next choice in the algorithm. However, numerous comorbidities may limit surgical intervention, especially given that diverticulosis is classically a disease of older individuals, who are known to have more comorbidities. Comorbidities in our patient relatively contraindicated surgery until the patient had no other alternative for hemostasis. Surgery may also be difficult given the lack of a specific site of bleeding in many of these patients, which was also seen in our patient [13]. Jensen reported that emergency colonoscopy with adequate colonic preparation has a higher diagnostic yield than elective colonoscopy [13] and found emergency colonoscopy to have had more diagnostic yield than angiography or tagged red blood cell scan [12]. Additonally, Jensen [13] implemented treatment modalties simultaneously using ultrasound to see the bases of bleeding vessels. Subsequently, Jensen's group used a combination of epinephrine, heat probe, and hemoclips at the base of bleeding diverticuli. India ink is also used to tattoo the bleeding vessel as a modality to monitor for future bleeds. Lastly, push enteroscopy was also useful in evaluating ongoing hematochezia or resolved hematochezia in the setting of a normal colonoscopy. This was established in the CURE Hemostasis trial mentioned by Jensen [13]. The CURE Hemostasis trial was a prospective trial of 500 consecutive patients with severe hematochezia who were evaluated by urgent colonoscopy. Patients that had a negative colonoscopy underwent push enteroscopy. This algorithm yielded more successful diagnosis and treatment in comparison to other gastroenterologic investigations. Following the conventional algorithm, our patient lacked a diagnosis until a coincidental diagnosis was made intraoperatively. We highlight Jensen's algorithm [13] to lower GI bleeding, which may have led to an earlier recognition of his bleeding based on Jensen's data.

Due to the $100 \%$ mortality rate of AE fistulas, treatment is absolutely essential. The options for treatment include either open surgical correction or endovascular stent placement. While open surgical correction of AE fistulas is the conventional treatment, this procedure is associated with high morbidity and mortality [3]. However, endovascular stent correction is associated with the risks of infection and recurrent bleeding [3]. The Journal of Vascular Surgery published a systematic review of stent repair 


\begin{tabular}{r|l|l|l}
$\begin{array}{r}\text { Case Reports in } \\
\text { Gastruenterology }\end{array}$ & $\begin{array}{l}\text { Case Rep Gastroenterol 2010;4:510-517 } \\
\text { DOI: 10.1159/000322662 }\end{array}$ & $\begin{array}{l}\text { Published online: } \\
\text { November 23, 2010 }\end{array}$ & $\begin{array}{l}\text { O 2010 S. Karger AG, Basel } \\
\text { ISSN 1662-0631 } \\
\text { www.karger.com/crg }\end{array}$ \\
\hline
\end{tabular}

outcomes for 41 patients, which found that persistent/recurrent/new infection or recurrent hemorrhage complicated the outcomes of $44 \%$ of patients in the study [3]. Preoperative evidence of sepsis was associated with poorer outcomes. Our patient underwent open surgical correction due to the fact that the fistula was only recognized intraoperatively. Additionally, his age and critical care status mandated a definitive treatment given the extent of secondary complications that he experienced.

\section{Conclusion}

AE fistulas can present with either upper GI or lower GI bleeding, and are universally deadly if left untreated. AE fistulas often present with a herald bleed before life-threatening bleeding. A careful history should always be elicited in patients with risk factors of AAAs such as hypertension, hyperlipidemia and a history of smoking. Strong clinical suspicion in the setting of a scrupulous patient history is the most important factor that allows for diagnosis of an AE fistula. There are numerous diagnostic modalities for AE fistula, but there is not one specific test that universally diagnoses AE fistulas. Nuclear medicine scans and angiography should not be completely relied on for the diagnosis of AE fistulas or other lower GI bleeds for that manner. Although the conventional paradigm for evaluating lower GI bleeds incorporates nuclear medicine scans and angiography, there is evidence that early endoscopy with enteroscopy may have a better role in severe lower GI bleeding.

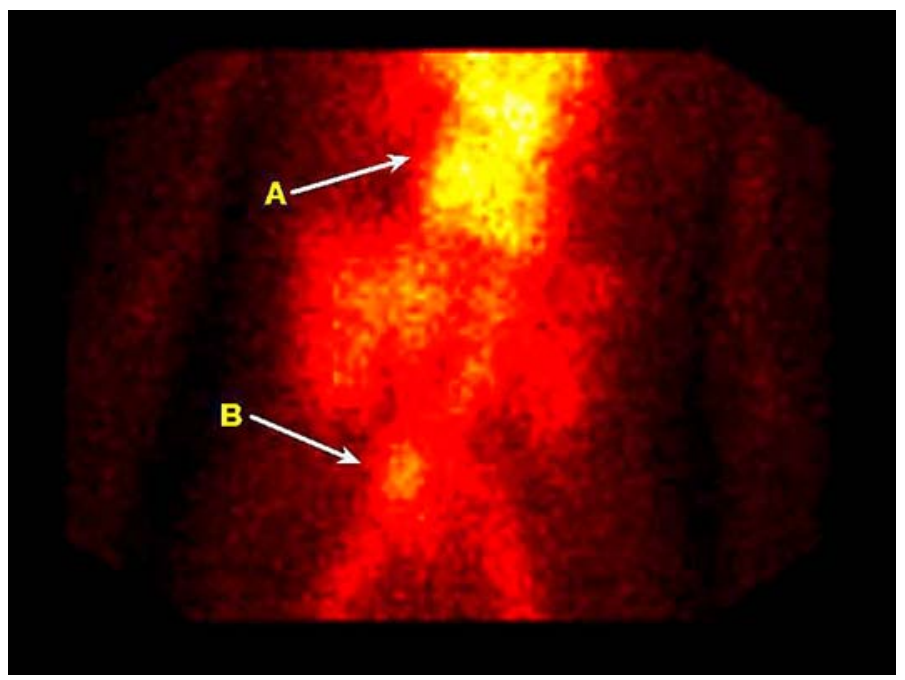

Fig. 1. Nuclear medicine bleeding scan showing increased uptake in the distal abdominal aorta (A) as well as the right common iliac (b), which was interpreted as physiological blood pooling that did not meet criteria for active lower GI bleeding. 


\begin{tabular}{r|l|l|l}
$\begin{array}{r}\text { Case Reports in } \\
\text { Gastruanterology }\end{array}$ & $\begin{array}{l}\text { Case Rep Gastroenterol 2010;4:510-517 } \\
\text { DOI: 10.1159/000322662 }\end{array}$ & $\begin{array}{l}\text { Published online: } \\
\text { November 23, 2010 }\end{array}$ & $\begin{array}{l}\odot \text { 2010 S. Karger AG, Basel } \\
\text { ISSN 1662-0631 } \\
\text { www.karger.com/crg }\end{array}$ \\
\hline
\end{tabular}

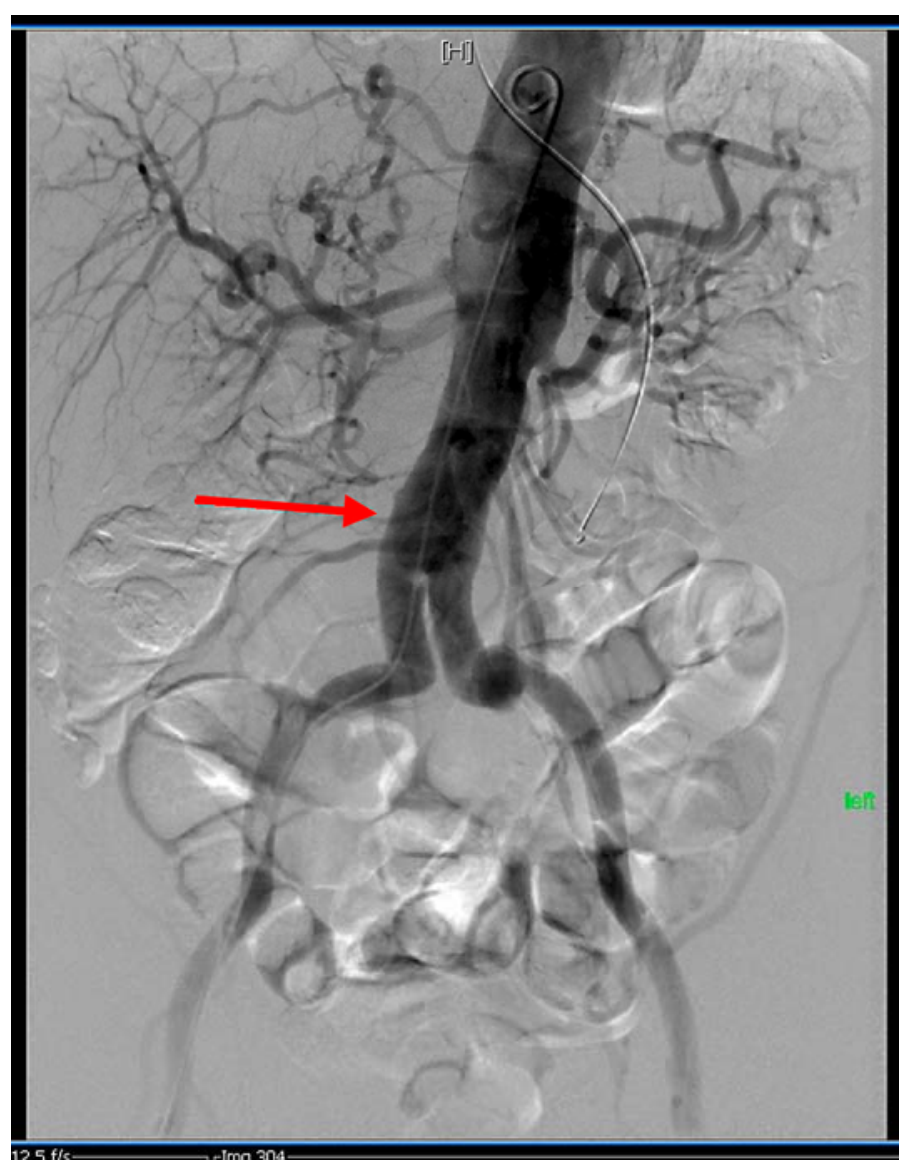

Fig. 2. Abdominal angiography revealing no evidence of bleeding, but an aorto-bi-iliac bypass graft with aneurysms distally. 


\begin{tabular}{r|l|l|l}
$\begin{array}{r}\text { Case Reports in } \\
\text { Gastruenterology }\end{array}$ & $\begin{array}{l}\text { Case Rep Gastroenterol 2010;4:510-517 } \\
\text { DOI: 10.1159/000322662 }\end{array}$ & $\begin{array}{l}\text { Published online: } \\
\text { November 23, 2010 }\end{array}$ & $\begin{array}{l}\text { @ 2010 S. Karger AG, Basel } \\
\text { ISSN 1662-0631 } \\
\text { www.karger.com/crg }\end{array}$ \\
\hline
\end{tabular}

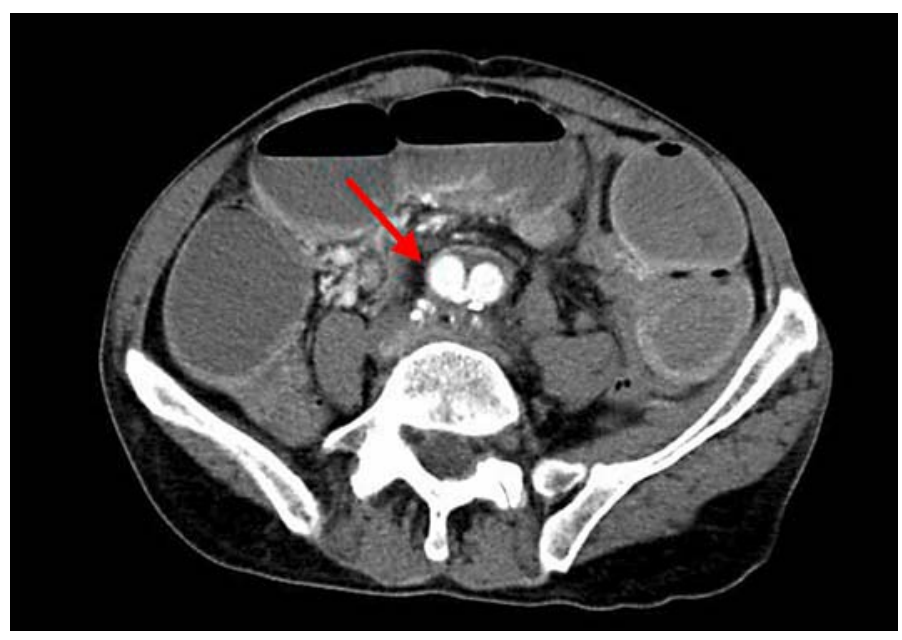

Fig. 3. An abdominal CT with contrast of our patient prior to his severe lower GI bleeding. Abdominal $\overline{\mathrm{CT}}$ shows an aorto-bi-iliac graft without evidence of an aortoenteric fistula or signs of graft site infection.

\section{References}

$\longrightarrow$ Wang WF, Huang QY, Yang YS: Primary aortoenteric fistula complicated by esophageal ulcer: case report. Chin Med J 2004;117:635-636.

-2 Ödemiş B, Başar Ö, Ertuğrul İ, İbiş M, Yüksel İ, Uçar E, Arda K: 2008. Detection of an aortoenteric fistula in a patient with intermittent bleeding. Nat Clin Pract Gastroenterol Hepatol 2008;5:226-230.

-3 Antoniou GA, Koutsias S, Antoniou SA, Georgiakakis A, Lazarides MK, Giannoukas AD: 2008. Outcome after endovascular stent graft repair of aortoenteric fistula: a systematic review. J Vasc Surg 2009;49:782-789.

4 Lauwers P, De Greef K, Van den Brande, et al: Aortic graft infection from appendicitis. A case report. Acta Chir Belg 2004;104:454-456.

5 Sears SJ, Scheltinga MR: Primary aortoenteric fistula. Br J Surg 2005;92:143-152.

6 Currie M, Wheat JM: Incidental findings on RBC gastrointestinal hemorrhage blood pool scintigraphy. Int J Nuc Med 2007;3:2, electronic source: www.ispub.com/journal/the_internet_journal_of_nuclear_medicine/ volume_3_number_2_35/article_printable/incidental_findings_on_rbc_gastrointestinal_haemorrhage_blood_ pool_scintigraphy.html (accessed Aug 7, 2010).

7 Crooke M, Currie G: RBC liver scintigraphy: an incidental finding of epistaxis. Int J Nuc Med 2006;3:1, electronic source: www.ispub.com/journal/the_internet_journal_of_nuclear_medicine/volume_3 number_1_36/article/rbc_liver_scintigraphy_an_incidental_finding_of_epistaxis.html (accessed Aug 7, 2010).

8 Antinori CH, Andrew CT, Santaspirt JS, et al: The many faces of aortoenteric fistula. Am Surg 1996;62:344.

-9 Zaman A, Katon RM: Push enteroscopy for obscure gastrointestinal bleeding yields a high incidence of proximal lesions within reach of a standard endoscope. Gastrointest Endosc 1998;47:372-376.

10 Kaushik S: Primary aortoenteric fistula. NZ J Med 1998;28:471-472.

$\checkmark 11$ Bookstein JJ, Naderi MJ, Walter JF: Transcatheter embolization for lower gastrointestinal bleeding. Radiology 1978;127:345-349.

12 Jensen DM, Machicado DA: Diagnosis and treatment of severe hematochezia: the role of urgent colonoscopy after purge. Gastroenterology 1988;95:1569-1574.

13 Jensen DM: 2009 Annual American College of Gastroenterology (ACG) Postgraduate Course, Evaluation and Management of GI Bleeding, pp 123-129. 